Chapter 4

\title{
Extracellular and Intracellular Barriers to Non-Viral Gene Transfer
}

\author{
Lynn F. Gottfried and David A. Dean \\ Additional information is available at the end of the chapter \\ http://dx.doi.org/10.5772/54699
}

\section{Introduction}

Non-viral gene therapy vectors are highly desirable tools for the introduction of DNA into cells; they have better safety profiles than viral methods of delivery and are more amenable to repeated administration. Non-viral vectors include naked DNA, cationic lipid-DNA complexes (lipoplex), polymer-DNA complexes (polyplex) or combinations of lipids and polymers. Successful gene delivery depends upon the ability of the vector of choice to target a specific cell type, enter the cell and obtain sufficient levels of gene expression. This is not a simple task since there are several barriers encountered by both viral and non-viral vectors that make this process difficult. First, the vector must have a method by which to target a specific cell type, while also avoiding extracellular insults including nucleases and the immune system. Next, once the vector has reached its particular target, it must traverse the plasma membrane and/or escape the endosome, and pass through the dense cytoskeletal network en route to the nucleus. The nuclear envelope presents a final barrier, since DNA must enter the nucleus in order to be transcribed. While viruses have evolved mechanisms to enter target cells, deliver their genetic material and continue to propagate, non-viral systems lack these innate mechanisms. Consequently, there has been much work aimed at characterizing and overcoming these barriers in order to improve the efficacy of these vectors.

\section{Extracellular barriers}

Regardless of the method by which a non-viral vector is administered in vivo (e.g., by inhalation, intramuscular injection, gavage, intravascular injection, etc), it will unavoidably come into contact with the extracellular environment. Within the extracellular milieu, multiple factors exist 
which can result in rapid clearance and/or degradation of the vector before it ever reaches its targeted organ. Intravenously delivered naked DNA has been shown to have a very short halflife within serum, on the range of 1.2 to 21 minutes depending upon the topoform of the DNA [1]. This is believed to be the result of both endo and exonuclease activity in the plasma. Similar degradation has been observed in plasmid DNA delivered intramuscularly [2]. Strategies to protect DNA from nuclease activity include the use of cationic lipids, such as DOTAP:DOPE, to encapsulate the plasmid and shield it from the enzymatic environment outside the cell [1]. In addition, the use of PEGylated lipids and polymers has been demonstrated to enhance the stability of complexes in serum, greatly lengthening the vectors' half-life [3].

DNA that does evade nucleases, however, also comes into contact with proteins and cells within the extracellular environment. Serum contains a variety of proteins which have the ability to bind to non-viral vectors and, as a result, inhibit the biological activity of the vector or sequester it for degradation and/or removal. For example, negatively charged serum proteins form connections between cationic liposomes, which results in the aggregration of the delivery vehicles. When this happens, the vectors are quickly removed from circulation by the reticuloendothelial system. Some of the key blood proteins that have been identified to associate with non-viral vectors include albumin, complement, immunoglobulins, fibronectin, apolipoproteins, C-reactive protein, and b2-glycoprotein I [4]. PEGylation of both lipolexes and polyplexes as well as the use of cholesterol as a helper lipid have shown promise in the prevention of this type of aggregation [3].

It is important to note that DNA delivery vehicles also come into contact with blood cells. These cells, which include erythrocytes, leukocytes, macrophages, and platelets, have a negative surface charge, thereby allowing for electrostatic interactions to occur between cells and cationic vectors. In particular, the interaction of lipoplexes with erythrocytes has been shown to be a significant factor in in vivo gene delivery, as binding occurs within minutes of in vivo intravenous gene transfer [5]. The vector is then able to directly associate (in the case of DOTMA/cholesterol complexes) and/or fuse (in the case of DOTMA/DOPE complexes) with erythrocytes, thereby decreasing transfection efficiency and encouraging removal of the delivery vehicle by way of the liver and spleen [5]. (Since erythrocytes have no nuclei, entry of vectors into these cells represents a dead end.) In the lung, the alveolar macrophage is regarded as a major barrier to both viral and non-viral delivery since this professional phagocytic cell "eats" up delivery agents before they can transfect any other cell type [6].

Another extracellular barrier to consider is activation of the immune system. While immune activation has been most associated with viral gene delivery, some non-viral methods have been shown to induce an immune response. For example, intravenously injected cationic lipoplexes can induce an inflammatory response involving the release of TNF $\alpha$ and IFN $\gamma$ into the serum [7]. This is believed to be a result of unmethylated CpG motifs on the plasmid DNA and the subsequent recognition by Toll-like receptors $[8,9]$. Thus, the removal of these CpG motifs is important for successful gene delivery [10]. The cationic polymer, PEI, has also been shown to activate the immune system through complement and activation of both a Th1 and Th2 response [11] Finally, as previously discussed, PEGylation of non-viral vectors is a common technique used for avoiding some extracellular barriers, however the production of 
anti-PEG IgM has the potential to interfere with repeated administration of the vector [12-17]. Thus, much care and consideration must be put into the selection of the proper non-viral vector for specific disease therapeutics.

\section{The plasma membrane}

Once the delivery vehicle has reached a cell, it then encounters a second significant barrier: the plasma membrane. Successful transfection relies on the ability of the vector to enter the cell of interest. In the absence of a delivery vehicle, naked DNA does not efficiently associate with the plasma membrane due to the negative charge density on both the DNA and the cell surface. Delivery vehicles help circumvent this problem through the use of polycations to neutralize the negative charge of the DNA, thereby increasing association with the plasma membrane. This non-specific electrostatic association is mediated largely by heparin sulfate proteoglycans on the cell surface that trigger endocytosis of the delivery vehicle and entry into the cell.

While most chemical transfection methods require endocytosis for transport across the plasma membrane into the cytoplasm, more recently, several short peptides have been reported to facilitate cell entry in an endocytosis-independent manner [18-20]. These have been termed cell-penetrating peptides (CPPs) and include peptides from proteins such as Tat, antennape$\mathrm{dia}$, and penetratin as well as polyarginine peptides. Depending upon the CPP used, different internalization mechanisms are used to access the cytoplasm including direct transduction through the lipid bilayer as well as energy-dependent macropinocytosis [21]. Regardless of the mechanism for cell entry, these peptides may prove very useful in delivery of small DNAs and synthetic RNAs.

Physical methods of gene delivery, such as the gene gun, electroporation (electric fields), sonoporation (ultrasound) and hydrodynamic (high pressure) delivery can also facilitate delivery of DNA across the plasma membrane. The gene gun utilizes metal particles coated with plasmid DNA that are accelerated and bombard a tissue of interest [22]. This technique, however is limited by the superficial penetration of the DNA into the tissue and is therefore most successful for percutaneous delivery of DNA. Electroporation is a more versatile technique that has been used on a variety of tissues with success. During this process, a series of electrical pulses are delivered that result in destabilization of the cell membrane. Transient pores are then created which allow the passage of plasmid DNA into the cell. Blood vessels, skin, muscle, heart, liver, and lung have all been successfully transfected with electroporation [23-27]. Sonoporation has seen most success in soft tissues and it's use deep within the body is a major potential strength. This technique uses ultrasound to enhance cell permeability through acoustic cavitation and subsequent gene transfer through passive diffusion of DNA across pores in the cell membranes. A number of in vivo studies have demonstrated successful gene transfer in skeletal muscle, cardiac muscle, kidney, carotid artery, pancreas and liver of mice and rats [28-37]. Finally, hydrodynamic gene delivery is a highly efficient method for gene transfer to highly perfused organs such as the liver or muscle in peripheral limbs. A large volume of DNA injected into the tail vein of a mouse has been shown to result in transient 
membrane changes in hepatocytes, resulting in direct transfer of DNA into the cytoplasm [38, 39]. Like electroporation and sonoporation, pores within the plasma membrane are thought to be formed allowing entry of plasmids, in this case by the rapid change in hydrostatic pressure [40]. Modifications of this technique using balloon catheters in larger animals has suggested potential for ultimate success in humans as well [41-43].

While all of these approaches facilitate endocytosis or direct entry into the cytoplasm of any cell type, one of the goals of gene therapy is often cell-specific targeting. Thus, the development of delivery vehicles that only interact with specific cell types is highly desirable. In most cases, cell-specificity is acheived by specific interactions between ligands on the vector and receptors on the cell surface. For example, as many tumor cells overexpress receptors for nutrients, such as folate and transferrin, this phentoype has been exploited for the development of DNA and drug delivery vehicles carrying either folic acid or transferrin as ligands. Recently, a transferrin-PEG-PE conjugated cationic lipid carrier and a PEG-transferrin-PEI nanocomplex were developed, which exhibited increased transfection efficiency in vitro as well as in vivo [44, 45]. Similar results have been obtained using folate linked nanoparticles as well [46]. Delivery of DNA to specific cell types has also been achieved through the use of glycosylated carriers, specifically cationic liposomes [47]. Mannosylated and galactose conjugated liposomes have demonstrated efficacy as delivery agents for macrophages and hepatocytes [48, 49].

\section{Vector release and cytoplasmic trafficking}

Gene delivery vectors that utilize endocytosis to access the cytoplasm are then moved through the endocytic compartment. Thus, another major barrier to successful gene delivery is the release of the DNA from the endosome before it is degraded at the lysosomal level. There are several mechanisms employed to increase the likelihood of endosomal escape including membrane fusion, the proton-sponge effect and incorporation of fusogenic and pore-forming peptides.

Lipoplexes are able to escape the endosome through fusion of the liposome with the endosomal membrane. In particular, inclusion of dioleoylphosphatidylethanolamine (DOPE) has been shown to enhance endosomal escape due to its ability to transition from bilayer to inverted hexagonal structures $[50,51]$. The instability of this type of structure increases fusion with endosomes and subsequently releases the DNA [52]. This is not common across all lipids as a similar phospholipid, dioleoylphosphatidylcholine (DOPC), does not exhibit similar activity [53,54]. Therefore, complex structure plays an important role in enhancement of endosomal escape.

In contrast to lipoplexes, cationic polymers such as PEI achieve endosomal escape through a 'proton sponge' mechanism. PEI possesses a very high buffering capacity due to the presence of amino nitrogen at every third atom, which can be protonated within the acidifying endosomes. Consequently, an accumulation of protons causes an influx of chloride ions thereby resulting in osmotic swelling and lysis of the endosome. Therefore, use of cationic polymers with this type 
of buffering capacity increases the amount of time before passage of DNA to lysosomes, which therefore increases the likelihood of the DNA getting transferred to the cytoplasm.

Finally, many fusogenic and pore-forming peptides have been discovered and incorporated into gene delivery vehicles. The influenza-derived peptides GALA and KALA undergo $\mathrm{pH}$-dependent conformational changes that result in disruption of endosomal membranes [55-58]. Several bacteria derived and animal derived peptides with membrane disruptive properties have also been developed and appear to increase endosomal escape and transfection efficiency [59].

Once DNA has successfully been released into the cytoplasm, it must then traffic to the nucleus in order for gene expression to occur. This step represents another significant barrier to gene delivery. First, the cytoplasm contains nucleases that will degrade free DNA. Studies have demonstrated that plasmid DNA is degraded in the cytoplasm of HeLa and COS cells with a half-life of 50 to 90 minutes [60]. This poses a big problem for delivery of naked DNA and DNA-lipid complexes that are believed to dissociate prior to nuclear entry. Additionally, the cytoplasm itself poses a diffusional barrier as well. The cytoplasm is a viscous environment crowded with molecules, which results in decreased mobility of macromolecules [61-63]. Thus, if DNA is released from an endosome at a distant site from the nucleus, the DNA cannot simply diffuse toward its desired location. This has been demonstrated in the case of liposome transfections where some DNA is left free in the cytoplasm and never reaches the nucleus [64, 65]. Although it has been shown that lipoplex-containing endosomes themselves traffic toward the nucleus and the interior of the cell, there is still quite a lot of distance for the free DNA following endosomal release to move before it reaches the nucleus. We and others have shown that DNA in the cytoplasm utilizes the microtubule network and the molecular motor, dynein [66-68] for its trafficking to the nucleus. Since DNA does not directly bind to dynein, the mechanism of this interaction was investigated and was found to involve a multiprotein complex that bridges the DNA and dynein. Our laboratory has shown that transcription factors are key proteins in this complex, and they are involved in the movement of DNA along microtubules [69]. Furthermore, the velocity of plasmid DNA movement can be increased through addition of specific transcription factor binding sites in the plasmid, such as CREB [69] or by inducing acetylation of the microtubules themselves [70]. The acetylation status is largely controlled by histone deacetylase 6 (HDAC6), and studies have shown that modulation of this enzyme can increase the efficiency of gene transfer [70]. Thus, despite the fact that the cytoplasm poses as a significant barrier to gene transfer, many techniques for overcoming this problem are being revealed.

\section{Nuclear import}

DNA that has successfully navigated all of the barriers previously discussed finally comes into contact with the nuclear envelope. However, depending upon cell type, DNA dose and detection method, only 1 to $10 \%$ of transfected plasmid can be found within the nucleus [71, 72]. This suggests that an overwhelming proportion of DNA that enters the cytoplasm will 
never successfully enter the nucleus. It has been appreciated for over 30 years that the nuclear envelope is a major barrier to DNA delivery [73]. Our laboratory has shown in microinjection experiments using non-dividing cells that 30 to 100 times more plasmid must be injected into the cytoplasm of a cell to equal levels of gene expression of plasmid injected directly into the nucleus [74]. While it is true that DNA delivery to the nucleus is greater within dividing cells, even breakdown of the nuclear envelope does not completely eliminate nuclear import as a barrier to transfer [75]. Therefore, studies aimed at understanding how DNA is imported into the nucleus as well as development of strategies to improve this process have been key to enhancing the efficiency of non-viral gene delivery.

A number of studies have shown that the vast majority of transfected DNA enters the nucleus during mitosis when the nuclear envelope has broken down [76, 77]. While plasmids can enter the nucleus in the absence of cell division, the process is slow and highly inefficient, resulting in very low levels of nuclear entry. However, our laboratory has shown that the delivery of plasmid DNA into the nucleus can be greatly increased by the addition of specific DNA sequences. We have demonstrated that plasmids containing only 72bp of the SV40 enhancer are able to target the nucleus of non-dividing cells within a few hours [78]. This sequence, termed a DNA nuclear targeting sequence (DTS), functions to enhance nuclear import in all cell types tested. It is the presence of ubiquitously expressed transcription factor binding sites within the SV40 DTS that mediate this effect. Since these transcription factors contain nuclear localization signals (NLS) to allow their targeting to the nucleus, nuclear import of the DNA is controlled by the interaction of these proteins with the NLS-receptors importin- $\alpha$ and importin- $\beta$, that then transport cargo through the nuclear pore complex (NPC). Thus, when NLS-containing transcription factors bind to the SV40 DTS on a plasmid, the plasmid utilizes this system to enter the nucleus $[79,80]$. We have shown that these DTS sequences act not only in microinjected cells, but in transfected cells as well to increase DNA nuclear uptake and gene expression as well as in tissues in living animals [81-83].

We have also identified several cell-specific DTSs, in which nuclear import of a plasmid is regulated by the presence of cell-specific transcription factor binding sites within the DTS. DTSs specific for smooth muscle cells, osteoblasts, endothelial cells, alveolar epithelial type I cells and alveolar epithelial type II cells have been identified and large studies are underway to screen hundreds of DNA sequences for the potential to act as cell-specific DTSs [83-86]. In all of these cases, the cell-specific DTS contains binding sites for cell specific transcription factors that are expressed in unique cell types. Thus, if the plasmid is delivered to a cell that expresses those transcription factors, it will be transported into the nucleus and gene expression will ensue; if, however, the plasmid enters any other cell type that does not express the specific transcription factor, the DNA will remain in the cytoplasm until cell division or until it is degraded by cytoplasmic nucleases. Again, as for the SV40 DTS, these cell-specific DTSs work in cultured cells and in animal tissues to increase gene expression in a cell-restricted manner [83, 86].

A number of other methods for enhancing nuclear import have been studied, all of which center around exploiting the cells protein nuclear import machinery. These approaches include complexing plasmid DNA with NLS peptides, nuclear proteins or small molecule ligands. The success of NLS peptides has been variable, likely due to the fact that the NLS must be visible 
to the importin proteins for nuclear import to occur [87]. However, in vivo studies using DNA with conjugated NLS peptides have demonstrated increased gene expression in muscle as well as increased immune response against the expressed antigen [88]. Also, more recently, analysis of a bipartite NLS construct as a non-viral gene carrier has revealed the potential success of this type of method over traditional monopartite peptides [89]. Due to the varied success of NLS peptides at promotion of nuclear import, it is still unclear if this will be a promising approach for gene therapy.

As an alternative to NLS peptides, some work has tested direct conjugation of importins to plasmid DNA. The importin- $\beta$-binding domain of importin- $\alpha$ was covalently coupled to plasmid DNA, but this also failed to enhance nuclear import [90]. In a separate study, a plasmid DNA/importin- $\beta$ conjugate was made via binding of biotinylated plasmid DNA and recombinant streptavidin-importin- $\beta$ chimeric protein. While this did enhance nuclear import, gene expression was very low due to the highly modified plasmid [91].

\section{Conclusion}

To maximize non-viral gene delivery, levels of expression must be improved. Unfortunately, many extracellular and intracellular barriers (including the extracellular environment, immune scavengers, the cell membrane, endosomal escape, the cytoskeletal network and the nuclear membrane) preclude efficient gene transfer. In this review, we have focused on these barriers and various means to overcome them. The goal of all gene therapy approaches is to target enough DNA to the nuclei of cells to obtain sufficient expression for a therapeutic effect. By characterizing and understanding these barriers, we can overcome our relative inability to target substantial amounts of DNA to the nucleus and increase transfection efficiency and ultimately gene therapy.

\section{Author details}

Lynn F. Gottfried and David A. Dean

Department of Pediatrics, University of Rochester Medical Center, Rochester, NY, USA

\section{References}

[1] Houk, B. E, Hochhaus, G, \& Hughes, J. A. Kinetic modeling of plasmid DNA degradation in rat plasma. AAPS PharmSci. (1999). E9.

[2] Mumper, R. J, Duguid, J. G, Anwer, K, Barron, M. K, Nitta, H, \& Rolland, A. P. Polyvinyl derivatives as novel interactive polymers for controlled gene delivery to muscle. Pharm Res. (1996). May;, 13(5), 701-9. 
[3] Sternberg, B, Hong, K, Zheng, W, \& Papahadjopoulos, D. Ultrastructural characterization of cationic liposome-DNA complexes showing enhanced stability in serum and high transfection activity in vivo. Biochim Biophys Acta. (1998). Oct 15;1375(1-2):23-35.

[4] Cullis, P. R, Chonn, A, \& Semple, S. C. Interactions of liposomes and lipid-based carrier systems with blood proteins: Relation to clearance behaviour in vivo. Adv Drug Deliv Rev. (1998). Jun 8;32(1-2):3-17.

[5] Sakurai, F, Nishioka, T, Saito, H, Baba, T, Okuda, A, Matsumoto, O, et al. Interaction between DNA-cationic liposome complexes and erythrocytes is an important factor in systemic gene transfer via the intravenous route in mice: the role of the neutral helper lipid. Gene Ther. (2001). May;, 8(9), 677-86.

[6] Mccray, P. B. Jr., Wang G, Kline JN, Zabner J, Chada S, Jolly DJ, et al. Alveolar macrophages inhibit retrovirus-mediated gene transfer to airway epithelia. Hum Gene Ther. (1997). Jun 10; 8(9), 1087-93.

[7] Dow, S. W, Fradkin, L. G, Liggitt, D. H, Willson, A. P, Heath, T. D, \& Potter, T. A. LipidDNA complexes induce potent activation of innate immune responses and antitumor activity when administered intravenously. J Immunol. (1999). Aug 1;, 163(3), 1552-61.

[8] Zhao, H, Hemmi, H, Akira, S, Cheng, S. H, Scheule, R. K, \& Yew, N. S. Contribution of Toll-like receptor 9 signaling to the acute inflammatory response to nonviral vectors. Mol Ther. (2004). Feb; 9(2), 241-8.

[9] Yasuda, K, Ogawa, Y, Yamane, I, Nishikawa, M, \& Takakura, Y. Macrophage activation by a DNA/cationic liposome complex requires endosomal acidification and TLR9dependent and-independent pathways. J Leukoc Biol. (2005). Jan; 77(1), 71-9.

[10] Hyde, S. C, Pringle, I. A, Abdullah, S, Lawton, A. E, Davies, L. A, Varathalingam, A, et al. CpG-free plasmids confer reduced inflammation and sustained pulmonary gene expression. Nat Biotechnol. (2008). May;, 26(5), 549-51.

[11] Regnstrom, K, Ragnarsson, E. G, Koping-hoggard, M, Torstensson, E, Nyblom, H, \& Artursson, P. PEI- a potent, but not harmless, mucosal immuno-stimulator of mixed Thelper cell response and FasL-mediated cell death in mice. Gene Ther. (2003). Sep; 10(18), 1575-83.

[12] Dams, E. T, Laverman, P, Oyen, W. J, Storm, G, Scherphof, G. L, Van Der Meer, J. W, et al. Accelerated blood clearance and altered biodistribution of repeated injections of sterically stabilized liposomes. J Pharmacol Exp Ther. (2000). Mar;, 292(3), 1071-9.

[13] Laverman, P, Carstens, M. G, Boerman, O. C, Dams, E. T, Oyen, W. J, Van Rooijen, N, et al. Factors affecting the accelerated blood clearance of polyethylene glycol-liposomes upon repeated injection. J Pharmacol Exp Ther. (2001). Aug;, 298(2), 607-12.

[14] Semple, S. C, Harasym, T. O, Clow, K. A, Ansell, S. M, Klimuk, S. K, \& Hope, M. J. Immunogenicity and rapid blood clearance of liposomes containing polyethylene glycol-lipid conjugates and nucleic Acid. J Pharmacol Exp Ther. (2005). Mar;, 312(3), 1020-6. 
[15] Ishida, T, Ichihara, M, Wang, X, Yamamoto, K, Kimura, J, Majima, E, et al. Injection of PEGylated liposomes in rats elicits PEG-specific IgM, which is responsible for rapid elimination of a second dose of PEGylated liposomes. J Control Release. (2006). May $1 ;, 112(1), 15-25$.

[16] Ishida, T, Wang, X, Shimizu, T, Nawata, K, \& Kiwada, H. PEGylated liposomes elicit an anti-PEG IgM response in a T cell-independent manner. J Control Release. (2007). Oct $8 ;$, 122(3), 349-55.

[17] Wang, X, Ishida, T, \& Kiwada, H. Anti-PEG IgM elicited by injection of liposomes is involved in the enhanced blood clearance of a subsequent dose of PEGylated liposomes. J Control Release. (2007). Jun 4; 119(2), 236-44.

[18] Thoren, P. E, Persson, D, Isakson, P, Goksor, M, Onfelt, A, \& Norden, B. Uptake of analogs of penetratin, Tat(48-60) and oligoarginine in live cells. Biochem Biophys Res Commun. (2003). Jul 18;, 307(1), 100-7.

[19] Vives, E, Brodin, P, \& Lebleu, B. A truncated HIV-1 Tat protein basic domain rapidly translocates through the plasma membrane and accumulates in the cell nucleus. J Biol Chem. (1997). Jun 20;, 272(25), 16010-7.

[20] Luedtke, N. W, Carmichael, P, \& Tor, Y. Cellular uptake of aminoglycosides, guanidinoglycosides, and poly-arginine. J Am Chem Soc. (2003). Oct 15;, 125(41), 12374-5.

[21] Raagel, H, Saalik, P, \& Pooga, M. Peptide-mediated protein delivery-which pathways are penetrable? Biochim Biophys Acta. Dec;(2240). , 1798(12), 2240-8.

[22] Yang, N. S, Burkholder, J, Roberts, B, Martinell, B, \& Mccabe, D. In vivo and in vitro gene transfer to mammalian somatic cells by particle bombardment. Proc Natl Acad Sci U S A. (1990). Dec;, 87(24), 9568-72.

[23] Heller, R, Jaroszeski, M, Atkin, A, Moradpour, D, Gilbert, R, Wands, J, et al. In vivo gene electroinjection and expression in rat liver. FEBS Lett. (1996). Jul 8;, 389(3), 225-8.

[24] Heller, R, Schultz, J, Lucas, M. L, Jaroszeski, M. J, Heller, L. C, Gilbert, R. A, et al. Intradermal delivery of interleukin-12 plasmid DNA by in vivo electroporation. DNA Cell Biol. (2001). Jan;, 20(1), 21-6.

[25] Hargrave, B, Downey, H, \& Strange, R. Jr., Murray L, Cinnamond C, Lundberg C, et al. Electroporation-mediated gene transfer directly to the swine heart. Gene Ther. Mar 29.

[26] Dean, D. A, Machado-aranda, D, Blair-parks, K, Yeldandi, A. V, \& Young, J. L. Electroporation as a method for high-level nonviral gene transfer to the lung. Gene Ther. (2003). Sep; 10(18), 1608-15.

[27] Mir, L. M, Bureau, M. F, Gehl, J, Rangara, R, Rouy, D, Caillaud, J. M, et al. Highefficiency gene transfer into skeletal muscle mediated by electric pulses. Proc Natl Acad Sci U S A. (1999). Apr 13;, 96(8), 4262-7. 
[28] Akowuah, E. F, Gray, C, Lawrie, A, Sheridan, P. J, Su, C. H, Bettinger, T, et al. Ultrasound-mediated delivery of TIMP-3 plasmid DNA into saphenous vein leads to increased lumen size in a porcine interposition graft model. Gene Ther. (2005). Jul; 12(14), 1154-7.

[29] Pislaru, S. V, Pislaru, C, Kinnick, R. R, Singh, R, Gulati, R, Greenleaf, J. F, et al. Optimization of ultrasound-mediated gene transfer: comparison of contrast agents and ultrasound modalities. Eur Heart J. (2003). Sep; 24(18), 1690-8.

[30] Guo, D. P, Li, X. Y, Sun, P, Tang, Y. B, Chen, X. Y, Chen, Q, et al. Ultrasound-targeted microbubble destruction improves the low density lipoprotein receptor gene expression in HepG2 cells. Biochem Biophys Res Commun. (2006). May 5; 343(2), 470-4.

[31] Sakakima, Y, Hayashi, S, Yagi, Y, Hayakawa, A, Tachibana, K, \& Nakao, A. Gene therapy for hepatocellular carcinoma using sonoporation enhanced by contrast agents. Cancer Gene Ther. (2005). Nov;; 12(11), 884-9.

[32] Azuma, H, Tomita, N, Kaneda, Y, Koike, H, Ogihara, T, Katsuoka, Y, et al. Transfection of NFkappaB-decoy oligodeoxynucleotides using efficient ultrasound-mediated gene transfer into donor kidneys prolonged survival of rat renal allografts. Gene Ther. (2003). Mar;, 10(5), 415-25.

[33] Chen, S, Shohet, R. V, Bekeredjian, R, Frenkel, P, \& Grayburn, P. A. Optimization of ultrasound parameters for cardiac gene delivery of adenoviral or plasmid deoxyribonucleic acid by ultrasound-targeted microbubble destruction. J Am Coll Cardiol. (2003). Jul 16; 42(2), 301-8.

[34] Kondo, I, Ohmori, K, Oshita, A, Takeuchi, H, Fuke, S, Shinomiya, K, et al. Treatment of acute myocardial infarction by hepatocyte growth factor gene transfer: the first demonstration of myocardial transfer of a "functional" gene using ultrasonic microbubble destruction. J Am Coll Cardiol. (2004). Aug 4;, 44(3), 644-53.

[35] Zhigang, W, Zhiyu, L, Haitao, R, Hong, R, Qunxia, Z, Ailong, H, et al. Ultrasoundmediated microbubble destruction enhances VEGF gene delivery to the infarcted myocardium in rats. Clin Imaging. (2004). Nov-Dec;, 28(6), 395-8.

[36] Chen, S, Ding, J. H, Bekeredjian, R, Yang, B. Z, Shohet, R. V, Johnston, S. A, et al. Efficient gene delivery to pancreatic islets with ultrasonic microbubble destruction technology. Proc Natl Acad Sci U S A. (2006). May 30; 103(22), 8469-74.

[37] Miao, C. H, Brayman, A. A, Loeb, K. R, Ye, P, Zhou, L, Mourad, P, et al. Ultrasound enhances gene delivery of human factor IX plasmid. Hum Gene Ther. (2005). Jul;; 16(7), 893-905.

[38] Liu, F, Song, Y, \& Liu, D. Hydrodynamics-based transfection in animals by systemic administration of plasmid DNA. Gene Ther. (1999). Jul;; 6(7), 1258-66.

[39] Zhang, G, Budker, V, \& Wolff, J. A. High levels of foreign gene expression in hepatocytes after tail vein injections of naked plasmid DNA. Hum Gene Ther. (1999). Jul 1; 10(10), 1735-7. 
[40] Zhang, G, Gao, X, Song, Y. K, Vollmer, R, Stolz, D. B, Gasiorowski, J. Z, et al. Hydroporation as the mechanism of hydrodynamic delivery. Gene Ther. (2004). Apr;, 11(8), 675-82.

[41] Eastman, S. J, Baskin, K. M, Hodges, B. L, Chu, Q, Gates, A, Dreusicke, R, et al. Development of catheter-based procedures for transducing the isolated rabbit liver with plasmid DNA. Hum Gene Ther. (2002). Nov 20; 13(17), 2065-77.

[42] Alino, S. F, Herrero, M. J, Noguera, I, Dasi, F, \& Sanchez, M. Pig liver gene therapy by noninvasive interventionist catheterism. Gene Ther. (2007). Feb;, 14(4), 334-43.

[43] Yoshino, H, Hashizume, K, \& Kobayashi, E. Naked plasmid DNA transfer to the porcine liver using rapid injection with large volume. Gene Ther. (2006). Dec;, 13(24), 1696-702.

[44] Wang, W, Zhou, F, Ge, L, Liu, X, \& Kong, F. Transferrin-PEG-PE modified dexamethasone conjugated cationic lipid carrier mediated gene delivery system for tumortargeted transfection. Int J Nanomedicine., 7, 2513-22.

[45] Lee, K. M, Lee, Y. B, \& Oh, I. J. Evaluation of PEG-transferrin-PEI nanocomplex as a gene delivery agent. J Nanosci Nanotechnol. Aug;, 11(8), 7078-81.

[46] Hofland, H. E, Masson, C, Iginla, S, Osetinsky, I, Reddy, J. A, Leamon, C. P, et al. Folatetargeted gene transfer in vivo. Mol Ther. (2002). Jun;, 5(6), 739-44.

[47] Hashida, M, Nishikawa, M, Yamashita, F, \& Takakura, Y. Cell-specific delivery of genes with glycosylated carriers. Adv Drug Deliv Rev. (2001). Nov 19;, 52(3), 187-96.

[48] Irache, J. M, Salman, H. H, Gamazo, C, \& Espuelas, S. Mannose-targeted systems for the delivery of therapeutics. Expert Opin Drug Deliv. (2008). Jun;, 5(6), 703-24.

[49] Wu, J, Nantz, M. H, \& Zern, M. A. Targeting hepatocytes for drug and gene delivery: emerging novel approaches and applications. Front Biosci. (2002). Mar 1;7:d, 717-25.

[50] Koltover, I, Salditt, T, Radler, J. O, \& Safinya, C. R. An inverted hexagonal phase of cationic liposome-DNA complexes related to DNA release and delivery. Science. (1998). Jul 3;, 281(5373), 78-81.

[51] Allen, T. M, Hong, K, \& Papahadjopoulos, D. Membrane contact, fusion, and hexagonal (HII) transitions in phosphatidylethanolamine liposomes. Biochemistry. (1990). Mar $27 ;$, 29(12), 2976-85.

[52] Noguchi, A, Furuno, T, Kawaura, C, \& Nakanishi, M. Membrane fusion plays an important role in gene transfection mediated by cationic liposomes. FEBS Lett. (1998). Aug 14;433(1-2):169-73.

[53] Farhood, H, Serbina, N, \& Huang, L. The role of dioleoyl phosphatidylethanolamine in cationic liposome mediated gene transfer. Biochim Biophys Acta. (1995). May 4; 1235(2), 289-95. 
[54] Mok, K. W, \& Cullis, P. R. Structural and fusogenic properties of cationic liposomes in the presence of plasmid DNA. Biophys J. (1997). Nov;, 73(5), 2534-45.

[55] Wyman, T. B, Nicol, F, Zelphati, O, Scaria, P. V, Plank, C, \& Szoka, F. C. Jr. Design, synthesis, and characterization of a cationic peptide that binds to nucleic acids and permeabilizes bilayers. Biochemistry. (1997). Mar 11; 36(10), 3008-17.

[56] Lee, H, Jeong, J. H, \& Park, T. G. A new gene delivery formulation of polyethylenimine/ DNA complexes coated with PEG conjugated fusogenic peptide. J Control Release. (2001). Sep 11;76(1-2):183-92.

[57] Min, S. H, Lee, D. C, Lim, M. J, Park, H. S, Kim, D. M, Cho, C. W, et al. A composite gene delivery system consisting of polyethylenimine and an amphipathic peptide KALA. J Gene Med. (2006). Dec;; 8(12), 1425-34.

[58] Parente, R. A, Nir, S, \& Szoka, F. C. Jr. Mechanism of leakage of phospholipid vesicle contents induced by the peptide GALA. Biochemistry. (1990). Sep 18;, 29(37), 8720-8.

[59] Varkouhi, A. K, Scholte, M, Storm, G, \& Haisma, H. J. Endosomal escape pathways for delivery of biologicals. J Control Release. May 10; 151(3), 220-8.

[60] Lechardeur, D, Sohn, K. J, Haardt, M, Joshi, P. B, Monck, M, Graham, R. W, et al. Metabolic instability of plasmid DNA in the cytosol: a potential barrier to gene transfer. Gene Ther. (1999). Apr;; 6(4), 482-97.

[61] Kao, H. P, Abney, J. R, \& Verkman, A. S. Determinants of the translational mobility of a small solute in cell cytoplasm. J Cell Biol. (1993). Jan;, 120(1), 175-84.

[62] Lukacs, G. L, Haggie, P, Seksek, O, Lechardeur, D, Freedman, N, \& Verkman, A. S. Sizedependent DNA mobility in cytoplasm and nucleus. J Biol Chem. (2000). Jan 21;, 275(3), 1625-9.

[63] Dauty, E, \& Verkman, A. S. Actin cytoskeleton as the principal determinant of sizedependent DNA mobility in cytoplasm: a new barrier for non-viral gene delivery. J Biol Chem. (2005). Mar 4; 280(9), 7823-8.

[64] Gao, X, \& Huang, L. Cytoplasmic expression of a reporter gene by co-delivery of T7 RNA polymerase and T7 promoter sequence with cationic liposomes. Nucleic Acids Res. (1993). Jun 25; 21(12), 2867-72.

[65] Zabner, J, Fasbender, A. J, Moninger, T, Poellinger, K. A, \& Welsh, M. J. Cellular and molecular barriers to gene transfer by a cationic lipid. J Biol Chem. (1995). Aug 11; 270(32), 18997-9007.

[66] Mesika, A, Kiss, V, Brumfeld, V, Ghosh, G, \& Reich, Z. Enhanced intracellular mobility and nuclear accumulation of DNA plasmids associated with a karyophilic protein. Hum Gene Ther. (2005). Feb; 16(2), 200-8.

[67] Vaughan, E. E, \& Dean, D. A. Intracellular trafficking of plasmids during transfection is mediated by microtubules. Mol Ther. (2006). Feb; 13(2), 422-8. 
[68] Salman, H, Abu-arish, A, Oliel, S, Loyter, A, Klafter, J, Granek, R, et al. Nuclear localization signal peptides induce molecular delivery along microtubules. Biophys J. (2005). Sep; 89(3), 2134-45.

[69] Badding, M. A, Vaughan, E. E, \& Dean, D. A. Transcription factor plasmid binding modulates microtubule interactions and intracellular trafficking during gene transfer. Gene Ther. Mar;, 19(3), 338-46.

[70] Vaughan, E. E, Geiger, R. C, Miller, A. M, Loh-marley, P. L, Suzuki, T, Miyata, N, et al. Microtubule acetylation through HDAC6 inhibition results in increased transfection efficiency. Mol Ther. (2008). Nov;, 16(11), 1841-7.

[71] Cohen, R. N, Van Der Aa, M. A, Macaraeg, N, Lee, A. P, \& Szoka, F. C. Jr. Quantification of plasmid DNA copies in the nucleus after lipoplex and polyplex transfection. J Control Release. (2009). Apr 17; 135(2), 166-74.

[72] Glover, D. J, Leyton, D. L, Moseley, G. W, \& Jans, D. A. The efficiency of nuclear plasmid DNA delivery is a critical determinant of transgene expression the single cell level. J Gene Med. Jan;, 12(1), 77-85.

[73] Cappechi, M. R. High efficiency transformation by direct microinjection of DNA into cultured mammalian cells. Cell. (1980). , 22, 479-88.

[74] Dean, D. A, Dean, B. S, Muller, S, \& Smith, L. C. Sequence requirements for plasmid nuclear import. Exp Cell Res. (1999). Dec 15;, 253(2), 713-22.

[75] Ludtke, J. J, Sebestyen, M. G, \& Wolff, J. A. The effect of cell division on the cellular dynamics of microinjected DNA and dextran. Mol Ther. (2002). May;5(5 Pt 1):579-88.

[76] Tseng, W. C, Haselton, F. R, \& Giorgio, T. D. Transfection by cationic liposomes using simultaneous single cell measurements of plasmid delivery and transgene expression. J Biol Chem. (1997). Oct 10;, 272(41), 25641-7.

[77] Brunner, S, Sauer, T, Carotta, S, Cotten, M, Saltik, M, \& Wagner, E. Cell cycle dependence of gene transfer by lipoplex, polyplex and recombinant adenovirus. Gene Ther. (2000). Mar;, 7(5), 401-7.

[78] Dean, D. A. Import of plasmid DNA into the nucleus is sequence specific. Exp Cell Res. (1997). Feb $1 ;$, 230(2), 293-302.

[79] Wilson, G. L, Dean, B. S, Wang, G, \& Dean, D. A. Nuclear import of plasmid DNA in digitonin-permeabilized cells requires both cytoplasmic factors and specific DNA sequences. J Biol Chem. (1999). Jul 30;, 274(31), 22025-32.

[80] Miller, A. M, Munkonge, F. M, Alton, E. W, \& Dean, D. A. Identification of protein cofactors necessary for sequence-specific plasmid DNA nuclear import. Mol Ther. (2009). Nov; 17(11), 1897-903.

[81] Vacik, J, Dean, B. S, Zimmer, W. E, \& Dean, D. A. Cell-specific nuclear import of plasmid DNA. Gene Ther. (1999). Jun;, 6(6), 1006-14. 
[82] Young, J. L, Benoit, J. N, \& Dean, D. A. Effect of a DNA nuclear targeting sequence on gene transfer and expression of plasmids in the intact vasculature. Gene Ther. (2003). Aug;, 10(17), 1465-70.

[83] Young, J. L, Zimmer, W. E, \& Dean, D. A. Smooth muscle-specific gene delivery in the vasculature based on restriction of DNA nuclear import. Exp Biol Med (Maywood). (2008). Jul;, 233(7), 840-8.

[84] Miller, A. M, \& Dean, D. A. Tissue-specific and transcription factor-mediated nuclear entry of DNA. Adv Drug Deliv Rev. (2009). Jul 2;61(7-8):603-13.

[85] Miller, A. M, \& Dean, D. A. Cell-specific nuclear import of plasmid DNA in smooth muscle requires tissue-specific transcription factors and DNA sequences. Gene Ther. (2008). Aug;, 15(15), 1107-15.

[86] Degiulio, J. V, Kaufman, C. D, \& Dean, D. A. The SP-C promoter facilitates alveolar type II epithelial cell-specific plasmid nuclear import and gene expression. Gene Ther. Apr; 17(4), 541-9.

[87] Sebestyen, M. G, Ludtke, J. J, Bassik, M. C, Zhang, G, Budker, V, Lukhtanov, E. A, et al. DNA vector chemistry: the covalent attachment of signal peptides to plasmid DNA. Nat Biotechnol. (1998). Jan;, 16(1), 80-5.

[88] (Choi Y, Jeon YH, Kang JH, Chung JK, Schmidt M, Kim AC. MIDGE/hNIS vaccination generates antigen-associated CD8+IFN-gamma+ $\mathrm{T}$ cells and enhances protective antitumor immunity. Int J Cancer. 2007 May 1;120(9):1942-50). 120(9), 1942-50.

[89] Matschke, J, Bohla, A, Maucksch, C, Mittal, R, Rudolph, C, \& Rosenecker, J. Characterization of KuNLS as bipartite nuclear localization sequence for non-viral gene delivery. PLoS One.7(2):e24615., 70(2)

[90] Carriere, M, Escriou, V, Savarin, A, \& Scherman, D. Coupling of importin beta binding peptide on plasmid DNA: transfection efficiency is increased by modification of lipoplex's physico-chemical properties. BMC Biotechnol. (2003). Sep 12;3:14.

[91] Nagasaki, T, Kawazu, T, Tachibana, T, Tamagaki, S, \& Shinkai, S. Enhanced nuclear import and transfection efficiency of plasmid DNA using streptavidin-fused importinbeta. J Control Release. (2005). Mar 2;, 103(1), 199-207. 